\title{
Undifferentiated carcinoma of stomach
}

INSERM

\section{Source}

INSERM. (1999). Orphanet: an online rare disease and orphan drug data base.

Undifferentiated carcinoma of stomach. ORPHA:423786

Undifferentiated carcinoma of stomach is a rare epithelial tumour of the stomach that lacks any features of differentiation beyond an epithelial phenotype. The presenting symptoms are usually vague and nonspecific, such as weight loss, anorexia, fatigue, epigastric pain and discomfort, heartburn and nausea, vomiting or hematemesis. Patients may also be asymptomatic. Ascites, jaundice, intestinal obstruction and peripheral lymphadenopathy indicate advanced stages and metastatic spread. 